\title{
Current Situation and Existing Problems of Factor Analysis Method
}

\author{
Liu Yun, Qiaowen Yang, Yonghong Yao, Guifen Ma* \\ Hua Shang Accounting College, Guang Dong University of Finance and Economics, Guang Zhou, China \\ Email address: \\ ly2005112@163.com (Liu Yun),yangqiaowen22@qq.com (Qiaowen Yang),24053907@qq.com (Yonghong Yao), \\ 3403671393@qq.com (Guifen Ma) \\ ${ }^{*}$ Corresponding author
}

\section{To cite this article:}

Liu Yun, Qiaowen Yang, Yonghong Yao, Guifen Ma. Current Situation and Existing Problems of Factor Analysis Method. Journal of Finance and Accounting. Vol. 7, No. 6, 2019, pp. 192-199. doi: 10.11648/j.jfa.20190706.12

Received: October 12, 2019; Accepted: November 7, 2019; Published: November 18, 2019

\begin{abstract}
Factor analysis is an important analytical method in psychology, medicine, economics, statistics, management and accounting. It is also widely used in various fields of social practice. This paper analyzes the history and development of factor analysis. It can be found from many teaching materials and social cases that factor analysis has many problems in the spread of knowledge in teaching materials and the practical application of society due to the defects in the theories and methods of factor analysis and difference analysis. The author believes that the fundamental reason lies in the fact that there is no scientific explanation for the difference formed by the interaction of various factors in the factor product equation of factor analysis. It is not only unscientific, correct and unfair to calculate the influence difference of factors, which can be used to evaluate the responsibility of the subject of economic activities and correct the deviation of experimental activities. The purpose of this paper is to discover and put forward problems on the premise of combing the application status of factor analysis and difference analysis, so as to lay a solid foundation for the subsequent discussion of "new methods of factor analysis and difference analysis". It is a prelude to the derivation of correct factor analysis and difference analysis methods.
\end{abstract}

Keywords: Factor Analysis, Interaction, Factor Differences

\section{Knowledge Points of Factor Analysis}

Factor Analysis Approach. It can be divided into qualitative analysis and quantitative analysis. Qualitative factor analysis is also called empirical analysis. This method mainly refers to the main and sub-factors (factors) that should be considered in the selection of value engineering objects, and the analysts determine the selection objects based on knowledge and experience. This method is simple and easy to use, which requires value engineers to be familiar with products and have rich experience, and adapt to the situation that the research objects are greatly different from each other or time is urgent, and can be combined with qualitative and quantitative analysis, which is a single and comprehensive method in comparative analysis.

Factor analysis, in the index system to analyze the degree of influence of various factors in the total change of phenomena, is a commonly used method of quantitative analysis of the influence of factors on the main factor quantity, its solution method includes the serial substitution method, difference analysis method, index decomposition method and so on. Factor analysis method is one of the important difference analysis methods in modern statistics, financial management, financial analysis, management accounting and other disciplines. It is also a branch of multivariate statistical analysis, multivariate regression (econometrics) empirical analysis, commonly used factor (factor) analysis. By using this method, researchers can simplify a set of quantitative data that reflects the nature, state and characteristics of things into a few intrinsic and quantitative characteristic factors that can reflect the correlation between things and determine the essence of things.

The factor analysis described in this paper is a specific form of quantitative factor analysis. The main factor is set as the explained variable (dependent variable), and its related factors (factors, explanatory variables) are analyzed in the form of factor product structure in the analysis formula. 


\section{Review of Factor Analysis}

\subsection{The Application of Factor Analysis Started from Intelligence Research}

In 1904, c. pearman put forward the "two-factor theory" of intelligence structure, namely, "G" factor (general factor) and "S" factor (special factor). In his article "objectively measured intelligence", he used factor analysis to study intelligence. When analyzing students' test scores, spearman observed that the correlation matrix between scores had some systematic influence. The correlation matrix is as follows: the course scores in the table are arranged in descending order of correlation coefficients from left to right, and in each row the values are generally reduced to the same degree. Spillman's analysis suggests that test scores in each subject can be viewed as the sum of a general factor (consistent with general intelligence) and a special factor (consistent with special intelligence). Most of the results were similar to those obtained by his various tests and calculations. Therefore, he believed that the content structure of any intelligence factor is composed of general factor $\mathrm{G}$ and special factor $\mathrm{S}$, which is known as the two-factor theory of intelligence.

American psychologist and psychological metrologists thurston Thurstone, L (ouis) L (eon) (1887.5.29 1955.9.29) and others by more than 60 different types of intelligence test, factor analysis from 60 many kinds of factors on extraction of 7 kinds of stable factor analysis as the key content, they are calculated, fluency, speech meaning of word, memory, reasoning, spatial perception and perceptual speed, called "basic psychological ability", created the intelligence of the period, group of factors theory. Thurston and colleagues tested each stable ability factor and predicted that these abilities should be negatively correlated. However, each ability is positively correlated with the others. There are still general factors among capabilities. They compiled PMAT test, and then carried out factor analysis on PMAT test data and found that there were still secondary group factors, namely language education ability, space machine ability and practical activity ability. In 1961, British psychologist P. E. Vernon put forward a hierarchical structure theory of intelligence, which established the highest level of intelligence as a general factor $\mathrm{G}$, and defined the language education ability, spatial mechanical ability and actual activity ability group with less influence as the sub-group factors of PMAT, and finally the special factor S. They used factor analysis to break intelligence down into hierarchical measures.

American psychologist j. p. gilford (1897-1987) 's theory of intelligence structure can be attributed to factor analysis. He proposed a three-dimensional model of intelligence structure, and believed that intelligence was composed of three variables, namely operation, content and result, which included five, four and six aspects respectively, with a total of 120 kinds of intelligence factors. Later, he increased the number of intelligence factors from 120 to 150 . To prove the existence of these 150 intelligence factors, he devised an intelligence test and verified it with factor analysis. He claims to have identified more than 100 intelligence factors, making it almost impossible to extract so many independent variables without factor analysis.

American psychologists Cattell (1963) and Horn (1968) conducted a secondary factor analysis of seven factors in thurston and found that there were not one but two main factors. The general intelligence factors are fluid intelligence GF and crystal intelligence GC. GF is loaded with number ability, spatial ability, reasoning ability, GC is loaded with language ability, reasoning ability, memory ability, word fluency. His theory supports spearman's theory of two factors of intelligence.

David wechsler (1896-1981), American medical psychologist and author of the wechsler intelligence test. Wexler is one of the greatest contributors to intelligence testing. His various intelligence scales are the most authoritative intelligence tests in the world today. The theoretical basis of intelligence test comes directly from spillman's intelligence two-factor theory and thurston's group factor theory. Merriam-webster believes that a person's general intelligence is a combination of many abilities, so his intelligence test benefits from factor analysis, which analyzes both the main factors and the factors. Kuhn (Cohen) of wechsler adult intelligence scale the predecessor of $\mathrm{W}-\mathrm{B}$, wechsler adult intelligence scale (WAIS) and wechsler school-age children intelligence scale (WISC) as the factor analysis, found the wechsler intelligence scale contains five common factors: language understanding I factors, perceptual organization, memory or attention, verbal understanding II, special class. Kaufman conducted a three-factor analysis of wisc-r and found that four verbal tests had higher perceptual organizational factor load, and three tests had higher memory or concentration factor load. There are scholars in China with the principal component analysis (pca) to the wechsler adult intelligence scale revised by combining with the actual situation of China's regional to (WAIS RC) based on urban and rural two norm and WAIS and WALS - R factor analysis, found that three kinds of scale factors have higher G load, test of four operations have higher load visual organization factors, there are three points test have higher memory or focus on the factors of load. The results of factor analysis are similar to those of Kuhn and kufman, which again proves the scientific nature of the wechler intelligence scale. But these are all based on econometric factor analysis, from the degree of relevance of explaining factors to the explained factors, to the factors that affect intelligence, or determine the composition of intelligence.

The factor analysis described in this paper is mainly the difference analysis of economics and management subject; It also ADAPTS to the factor difference analysis of different experimental results in physics and chemistry.

\subsection{Factor Analysis}

The significance of factor analysis is to use quantitative difference analysis method to analyze the external characteristics and connections of observable things in the development from the main to the secondary, from the surface to the inside, from one to the other, from the rough to the 
essence, and from the false to the true, so as to get the general nature of objective things. Secondly, factor analysis can not only summarize the main factors, but also simplify and refine them to sub-factors, make complexity become simplification, and make multivariate generalization into the integration of information content of units.

Management: micro, set the main factor (explained factor) operating income, its increase or decrease can be explained by the increase or decrease of sales volume and sales price in the factor of operating income. Roe can be explained by the factor increase or decrease of net selling interest rate, asset turnover rate and equity multiplier.

Macroscopically, by analyzing the supply and demand of futures commodities and their influencing factors, the method of explaining and predicting the trend of futures price changes is proposed. Futures trading is based on spot trading. Futures prices are closely linked to spot prices. The situation of commodity supply and demand and the many factors affecting its supply and demand have an important impact on the price of commodities in the spot market, which will inevitably have an important impact on the futures price. Futures prices are affected not only by the supply and demand of commodities, but also by many other non-supply and demand factors. Non-supply and demand factors include: financial and monetary factors, political factors, policy factors, speculative factors, psychological expectations and so on. Therefore, in addition to considering supply and demand, the factor analysis of futures price trend also needs to comprehensively consider the influence of macro factors.

The law of economic value shows that the price fluctuates around the value under the influence of supply and demand. The basic factor analysis mainly analyzes the relationship between supply and demand. The change of commodity supply and demand condition and price change affect and restrict each other. The price of commodities is inversely proportional to the supply. Supply goes down, prices go up. The price of commodities is in direct proportion to the demand Demand goes down, prices go down. If other factors remain unchanged, any change in supply and demand may affect the change in commodity price. On the one hand, the change in commodity price is affected by the change in supply and demand. On the other hand, changes in commodity prices in turn have an impact on supply and demand. Prices go down, supply goes down, demand goes up. This mutual and cause-and-effect relationship between supply and demand and price complicates the analysis of commodity supply and demand, that is, not only the influence of supply and demand changes on price, but also the reaction of price changes on supply and demand should be considered. In the interpretation of operating income (sales income), in addition to selecting demand and price factors, management science can also use factor expansion method to introduce operating cost, tax and other factors, and analyze the influence of each factor on the increase or decrease of main factor operating income from the perspective of factor analysis on the change of factor difference.

Factor analysis is widely used in econometrics, statistics, financial management, financial analysis, management accounting, cost management accounting, auditing, etc.

\subsection{Modern Application of Factor Analysis Method}

Chen gang [1] on the statistics and decision making in the factors based on FTA analysis method of performance evaluation of enterprise marketing ", select part of the hydropower enterprise marketing performance data in 2017 in gansu province as the research object, in the construction of electric power marketing effect, on the basis of the evaluation index system, combining with defect tree (FTP) and factor analysis method to step by step a trace of key indicators, precise positioning key indicators and marketing weak links, and to find the root cause of the decline in marketing performance and put forward effective solutions. The results show that the main weak links in the marketing of hydropower enterprises in gansu province are the decrease of water supply caused by the lack of rainfall and the depletion of water sources. The spatial structure of sales electricity is unreasonable (beta $=0.862$ ), thus providing a theoretical basis for improving the marketing efficiency of power enterprises in gansu. The application of factor analysis method in economic management of hydropower enterprises is presented.

Li yong [2] wrote "application of factor analysis method in the purchase and sale performance appraisal of stored grain". In the operation and management of enterprises, there are various factors that affect business results. The use of factor analysis method to evaluate the influence degree of various aspects is conducive to the correct evaluation of the company's business performance. This paper analyzes and studies the performance evaluation of grain rotation in China, and explores the objective evaluation by establishing standard value and using factor analysis method. The application of factor analysis method in grain storage is explained.

Rindia [3] to the factor analysis method in the application of the standard cost variance analysis in daily financial management, financial analysis is based on financial statements and other information, using specific methods, related to the enterprise economic activity, profit ability, operation ability, debt paying ability and development capacity analysis and evaluation of the economic management activities. As an analysis method, factor analysis method is widely used in daily financial analysis. It shows that factor analysis is widely used in standard cost variance analysis.

With the popularity of the Internet and the arrival of the era of big data, the fast logistics and effective electronic payment and settlement, e-commerce enterprises have become a popular industry [4]. Compared with traditional retail enterprises, e-commerce enterprises have various business models and complex business. In the case of frequent financial risks, the sustainable operation of e-commerce industry needs to improve the ability of operating financial analysis urgently. In this paper, according to the core of the financial analysis indicators, return on equity (also known as return on equity), for example, choose the $\mathrm{Su}$ Ningyun business enterprises (2012-2014) 3 a-share code 002024) analysis of financial statement data as sample, using factor analysis method to 
carry out empirical analysis, it is concluded that electricity enterprise's business performance, operational efficiency and the ratio of the capital structure of the situation, put forward the electric business enterprise feasible Suggestions to improve overall operating efficiency.

Gao Juqi [5] post the factor analytic method to differentiate from material cost analysis to three yuan "think: material cost analysis, for example, with dual factor analysis first, then according to the three factors, for example, two different methods and comparison (that is, the three factors by ordinal replace) during the reporting period and base period, analysis the meaning which method is more close to the economy, through analysis, found that among the three factors to replace if there is a caliber inconsistent, lack of economic meaning, explain random replacement is not matching, three factors are not economic analysis and guidance significance. Therefore, according to the internal economic causal relationship, according to the degree of tightness in order, and then conduct index analysis to guide economic activities with scientific methods. This paper finds that there are some problems in factor analysis, but no theoretical evidence is found from mathematical analysis. There is no fundamental solution to the problem of factor analysis.

Li haiying [6]. Based on the application of factor analysis method in financial analysis of automobile enterprises, it is believed that the competition in automobile market is becoming increasingly fierce, so how to ensure profitability and promote sustainable development is crucial for enterprise development. Combined with work practice, this paper discusses and discusses the application of factor analysis method in the financial analysis of automobile enterprises, in order to help analyze the key factors affecting the profitability, and then effectively control, to ensure the ultimate realization of enterprise profitability goals. Explain the application of factor analysis method in enterprise performance analysis and evaluation.

Hai Tao Liu Si-zong Guo [7] post the reasoning model of factor analysis method, to solve the problem caused by incomplete due to sample the factor analysis method can't identify problems, define the factors respectively correlation matrix, the basis of attributes analysis table, integrity, the similarity between the concepts, such as the reasoning model based on factor analysis is proposed. The verification results show that the model can not only solve the problem of non-recognition, but also has a high identification rate. This paper addresses how to establish a factor analysis model in the case of econometric model factor analysis and lack of variables. Liu ying [8] studied and analyzed the application of factor analysis method in electric power marketing in "application of factor analysis method in electric power marketing". Explain the application of factor analysis in electric power management. Zhang Qingling, Zhang Liyuan [9] the factor analytic method to improve exploration for direct material costs - for example, in the accounting communication dispatch by analyzing the factors affecting the cost, find out the main cause of cost increase or decrease, the root of the cost issues, in order to find direction for the future cost management work, so as to realize authors efficiency. Many enterprises will use factor analysis method, one of the quantitative analysis methods of cost statements, to analyze and calculate the relevant data reflecting the financial status and operating results of enterprises according to cost statements and other relevant materials, so as to reveal the relationship between various data and determine the impact of each factor on the target object. This paper emphasizes the application of cost factor analysis using report data.

Wang jinyu [10] article "discussion on the application of factor analysis in financial management" thinks: financial management is an important management system of enterprises, there are many financial analysis methods in financial management, factor analysis is one of the important methods. This article first elaborated the factor analysis the connotation, secondly analyzed our country present financial management existence malpractice, finally used the case to discuss the factor analysis method in the financial management application. This paper does not fundamentally solve the problem of factor analysis.

Zhang wenhai and wang fei [11] used the traditional factor analysis method in "correction of factor analysis -- based on spatial analysis of three factors" to select the replacement order of factors with certain subjective judgment, which may lead to errors in the analysis. In this paper, the essence of the three-factor spatial analytical analysis of the factor analysis method, the use of mathematical model to modify the traditional factor analysis method, can be more accurate to obtain the impact of the change of each influencing factor on the change of the target object. This paper finds that the "substitution order" in the factor analysis method is misleading, and the root cause of misleading is the unfair distribution of factor interaction.

Grace pang [12] to the factor analysis method in the application of standard cost management, cost management is discussed in the standard cost management mode, on the basis of standard cost analysis and factor analysis, the flexibility to use factor analysis method to the calculation of standard cost variances, which greatly simplifies the cost variance analysis. This paper deals with the problem of comparison standard of difference analysis in factor analysis.

Chen Yiyun [13] in the "friends of the accounting" post "based on the analysis of rate of return on total assets factor analytic method to trap", based on financial indexes, total assets return rate, for example, on the basis of factor analysis, the calculation steps are analyzed in the existing in the use of a variety of trap, namely the calculation process with subjective assumption, a replacement order, arrangement, diversity, irreversible, such as trap, and put forward the corresponding countermeasures against these traps, in order to improve the effectiveness of financial analysis. The author finds out the case problems in the application of factor analysis, but does not reveal the root causes of many problems. There is no scientific way to solve the problem.

To sum up, it can be summarized as follows: Factor analysis method is widely used in psychology, medicine, econometrics, statistics and management (financial management, financial 
analysis, management accounting, cost accounting and auditing); There are many problems in the practical application of factor analysis method, especially in the application of factor analysis to differential analysis. This topic tries to find out the root cause of the problem, find out the scientific method to solve the problem, and make the factor analysis difference analysis more widely, scientifically and correctly used in social practice.

\section{Factor Analysis and Calculation Method}

The calculation method of factor analysis is mainly the difference analysis of factors. In the factor and structure of factors, the sum of differences affected by factors is equal to the difference of main factors. In the case of factor product structure of principal factors, the influence of factors on principal factors cannot be simply explained by the sum of factor influence quantity. This is because of the interaction between factors, that is, the influence of co-variation between factors on the variation difference of main factors.

\subsection{Factor Analysis Procedures}

a. Determine the basic equation of the analysis. The dependent variable is regarded as the main factor, and the independent variable is called the factor (factor); There are equation structural relationships among the factors.

b. Calculate the difference of main factors, also known as the analysis object, the total difference.

c. Calculate the influence quantity of factors on main factors, i.e. the difference of factor influence quantity.

d. Verification: add the influencing factors to verify whether the sum is equal to the total difference of the main factors. If equal, the calculation is correct; If not, the calculation is wrong. The substitution process needs to be checked for errors so that correct answers can be obtained after correction.

\subsection{Serial Replacement}

It is to analysis the main index is decomposed into quantifiable factors (factor), and according to the main factors of structural formula of the interdependent relationship between factor in (model or formula), comparing the factors of value (usually the actual values) replacement value (is a standard of comparison is usually standard or average value, the value of the last year, or the same industry plan, enterprise value benchmarking, etc.), which determine the influence of various factors on the analysis of the main factors.

For example, suppose a certain main factor index $\mathrm{K}$ is obtained by multiplying three interrelated factors $\mathrm{a}, \mathrm{b}$ and $\mathrm{c}$, and $\mathrm{K}_{1}$ reporting period (actual) index and $\mathrm{K}_{0}$ are the average level of the same industry, and analyze the difference between the actual completion number and the average level of the same industry: a. Basic equation of analysis:

$$
\mathrm{K}=\mathrm{a} * \mathrm{~b} * \mathrm{c} \ldots
$$

Reporting period indicators

$$
\mathrm{K} 1=\mathrm{a} 1 * \mathrm{~b} 1 * \mathrm{c} 1
$$

Base (planning) indicator

$$
\mathrm{K} 0=\mathrm{a} 0 * \mathrm{~b} 0 * \mathrm{c} 0 .
$$

b. Calculate the overall analysis difference

$$
\Delta \mathrm{K}=\mathrm{k}_{1}-\mathrm{k}_{0}=\mathrm{a}_{1} * \mathrm{~b}_{1} * \mathrm{c}_{1}-\mathrm{a}_{0} * \mathrm{~b}_{0} * \mathrm{c}_{0}(2)-(3)
$$

c. Analysis factors influence differences

$$
\text { Replace } a_{1} * b_{0} * c_{0} \text { for the first time... }
$$

Influence of factor a: (4) - (3)

$$
\text { Replace } a_{1} * b_{1} * c_{0} \text { for the second time... }
$$

Influence of factor b: (5) - (4)

Replace $a_{1} * b_{1} * c_{1}$ for the third time...

Influence of $C$ factor: (2) - (5)

d. Taking all the changes of factors into consideration, the total impact:

$$
\Delta \mathrm{K}=\mathrm{K}_{1}-\mathrm{K}_{0}=(2)-(3)=(4)-(3)+(5)-(4)+(2)-(5)
$$

\subsection{Differential Substitution}

It is a simplification of the serial substitution method, which USES the difference between the analytical value of each factor and the standard value to calculate the influence of each factor on the main factor index of the analysis.

For example, financial index $\mathrm{K}$ is still the main factor, and the structural relationship of three factors $A, B$ and $C$ is the product of factors. $K_{l}$ is the actual completion number, and $K_{0}$ is the budget number. Analyze the difference between the actual completion number and the budget number.

a. Basic equation of analysis:

$$
\mathrm{K}=\mathrm{A} * \mathrm{~B} * \mathrm{C}
$$

b. Analysis object, i.e. principal factor difference or

$$
\Delta \mathrm{K}=\mathrm{k} 1-\mathrm{k} 0=\mathrm{A} 1 * \mathrm{~B} 1 * \mathrm{C} 1-\mathrm{A} 0 * \mathrm{~B} 0 * \mathrm{C} 0
$$

c. Influence quantity of factors:

Influence of factor a:

$$
\triangle \mathrm{A} * \mathrm{~B} 0 * \mathrm{C} 0
$$

factor influence:

$$
\mathrm{A} 1 * \Delta \mathrm{B} * \mathrm{C} 0
$$

factor influence:

$$
\mathrm{A}_{1} * \mathrm{~B}_{1} * \Delta \mathrm{C}
$$

d. Verification: $(7)=(8)+(9)+(10)$ 
Compared with the two methods, the obvious differential substitution is simpler than the serial substitution. Exponential method is no longer redundant.

\section{Factor Analysis and Evaluation}

\subsection{Ignoring Interaction We Call the Explained Factors in Factor Analysis Main Factors}

(also known as dependent variables), and the explanatory factors in factor analysis factor factors, or factors (also known as sub-factors, also known as independent variables). This exists in mathematical function formula, physical formula, chemical equation, biological structure formula, economics, management is also called model. In product structure model, when we analysis different period, different dispersion experiment and practice of the main factors change, the interactions between factors, namely two or more than two factors of changes on the dispersion of the change of main factors, the influence of factors between the mutual change to be explained variables, the effects of what we call the interaction. However, the current factor analysis ignores the interaction between factors. As the main factor of sales revenue, there are two factors: sales price $\mathrm{p}$ and sales quantity $\mathrm{x}$, its structure model for the product form: $y=p * x$, when we analyze the difference in sales income in different periods $\Delta y=y_{1}-y_{0}=p_{1} * x_{1}-p_{0} * x_{0}$, where $\Delta p^{*} \Delta x$ for $\Delta y$, is the interaction between factor price and sales volume. In $K=A *$ $B * C$ factors $A, B, C$, also $\Delta A * \Delta B * C_{0}, \Delta A * \Delta C * B_{0}$, $\Delta C^{*} \Delta B * A_{0}, \Delta A * \Delta B * \Delta C$ four interactions.

\subsection{Adding Constraints}

Since the current factor analysis does not recognize (or omit) the interaction between factors, some restrictions are added in the calculation of factor analysis, such as "substitution order", "quantity first, quality later", "factor hypothesis", "answer hypothesis", etc. In particular, the assumption of substitution sequence has become a condition to modify the calculation error, because different order substitution will result in different factors, which is inconsistent with the uniqueness, scientificity and veriability of the calculation results. In the difference analysis of the correct factor analysis, some assumptions are redundant.

\subsection{Breeding New Factors}

Some cases turn the factor analysis into a chemical equation, creating other factors in the factor factor. In the sales revenue model, $y=p^{*} x$, which was originally only two factors, some textbooks even generate "structure" or "level" influence in addition to the existing price and sales factor. In the influence of cost, the influence of "efficiency" factor arises.

When $y=p^{*} x$, when the two factors are combined, there is a combination of $p_{1} * x_{1}, p_{1} * x_{0}, p_{0} * x_{1}$ and $p_{0} * x_{0}$ in the serial substitution method. The two formulas cannot explain three of the four combinations of the differences. Where is $p_{0}{ }^{*} x_{l}$ in the current calculation? Results the extra combination and interaction are turned into the "structure" of breeding factors, and the previously calculated quantitative influence is turned into the "quantity + structure", and the former influence of price factor is turned into the "price + grade". These breeding factors of "structure" and "grade" coincide with the existence of factor interaction. Factor analysis differential analysis in economic management, like the chemical equation, produces new factor variables. Structure and grade are compound factors, which cannot be explained by a single factor. When structure and grade explain value, they can only be multiplied by quantity and price and compared with overall value. Single quantity or single price cannot explain the ratio of value. It's a little bit redundant to explain the main factors here.

\subsection{Acknowledge Interaction}

Admittedly, there are some works that acknowledge the interaction between factors in the analysis of factor analysis difference, and generally treat them as follows:

1) Recognize that there are interactions between factors in the calculation of factor analysis, which have little or no impact on the increase or decrease of main factors. Considering that the method of factor analysis has become a pattern, it follows the trend; And there is no right way to replace it, so it is default. Don't bother to study, explore and correct. Financial analysis of the calculation method will be wrong, inherit, wrong.

2) Recognize the interaction between factors in the calculation process of factor analysis. In the above equation, first calculate the main factor of the overall difference in sales revenue delta $y$, and then calculate the influence of price factors $\Delta p^{*} x_{0}$, sales factors affect $p_{0} * \Delta x$; Interaction items with multiple $\Delta y-\Delta p^{*} x_{0}-p_{0} *$ $\Delta x$; There are only two factors and the result calculated with delta $\mathrm{p}^{*}$ delta $\mathrm{x}$ is called "factor interaction." The results of the analysis, directly defined as: price factors on sales revenue, sales volume factors on sales revenue, price and sales volume interaction on sales revenue, three total impact of $\Delta y$. This recognition of the fact, but does not quantize the exchange effect, inconvenient to understand.

3) Econometrics (3rd edition)[14] by James h. stock, translated by Mark w. Watson, translated by shen genxiang and sun yan, published by gezhi press in April 2015, 4th edition, defining multiple regression definition: "the interaction term of two independent variables $x_{1}$ and $x_{2}$ is their product $x_{1} * x_{2}$. When you add this interaction term, the effect of changes in $x_{1}$ on $y$ depends on the value of $x_{2}$, whereas the effect of changes in $x_{2}$ depends on $x_{1}$. The coefficients of $x_{1}$ times $x_{2}$ are greater than the sum of the effects of $x_{1}$ plus one unit and $x_{2}$ plus one unit. It doesn't matter if $x_{1}$ and/or $x_{2}$ are continuous or binary variables. This shows that in econometrics, the interaction between factors is considered in the selection of variables and structures.

4) Decomposition incremental influence recognize the interaction among factors in the difference analysis of factor analysis, and decompose the interaction by exponential method. In his book statistics, professor xu 
guoxiang used exponential method to solve the problem of interaction increment in factor analysis difference analysis, and had a case demonstration. Whether the index method is Mr Xu's work, or not, his students have taken their dispute to the academic committee of the Shanghai university of finance and economics. Whatever the outcome of the dispute, at least our theoretical, economic and management circles have responded to and cracked the problem of factor analysis.

5) spread of existing methods

The current method of factor analysis spreads not only in the practical writing of economic management; It can be found everywhere in all kinds of textbooks [15].

Charles t. Horngren (1926 2011), emeritus professor of accounting at Stanford university, was inducted into the accounting hall of fame. As a member of the American institute of accounting, he served as President and director of research, and was awarded the distinguished accounting educator award by the American institute of accounting in 1973. As a member of the American institute of management accountants, received the distinguished service award. The California foundation for certified public accountants has awarded the hungaray distinguished achievement award and the distinguished professor award, both of which he received. Srikant $\mathrm{m}$. Datar is a professor at harvard business school. Mr. Datar has a strong teaching reputation, winning the organization of teaching award at Carnegie Mellon university and the outstanding educator award at Stanford university. Madhav v. rajan is a professor at Stanford university's business school and law school. In 2004, he received the distinguished contribution award for management accounting from the American accounting institute.

Cost and management accounting by Charles Thomas Horngren (1926 2011) [16], with Srikant m. duatar Madhav v. rajan (15th edition, translated by liyan wang and yingwen liu, China renmin university press, 3rd printing in November 2017) p198-260, flexible budget, direct cost difference and Management control, Horngren, Charles t., Alnoor Bhimani, Srikant m. Datar, and George Foster. Management and cost accounting. Harlow: Financial Times/Prentice Hall, $2002 / 2008$. In the difference analysis, the traditional factor analysis is adopted in the whole chapter, and the interaction between factors is not considered, but rather the interaction between factors is explained by the generated variables.

Srikant m. dal, Madhav v. ajan management accounting (translated by wang liyan, Chen jiashi, 1st edition, renmin university of China press, April 2015), chapter 13, flexible budget, difference and management control p450-491, in which the difference analysis is mostly factor analysis, and the solution method remains the same. This book shares two of the authors of cost management accounting.

The 14th edition of the original book Financial Accounting, Roman 1. eil, Katherine Schipper, Jennifer Francis [17].

Zhang Xianzhi, Chen Youbang in northeast university of finance and economics ) are "financial analysis" (" twelfth five-year "national plan of undergraduate course of common higher education textbooks, national excellent courses, state-level high-quality goods resource sharing class 37 times printing) in May 2018 the book with a few chapters no factor analysis, factor analysis method of dozens of cases, are used in serial alternative method or the difference substitution method [18].

The first edition of financial cost management, which was organized and compiled by the Chinese institute of certified public accountants, was published by China financial and economic publishing group and China financial and economic publishing house in March 2018, in which the interaction of factor analysis in the product structure was not considered [19].

Cost management accounting by meng yan and liu junyong [20] (higher education press printed a series of textbooks for accounting majors in colleges and universities for the third time in December 2017, as well as national planning textbooks for undergraduate students of general higher education during the 12th five-year plan). Tracie Nobles, Brenda Mattison, Ella Mae Matsumura. Horngren's accounting: management accounting sub-volume (the fourth edition of the original book), mechanical industry press, January 2017, 1st edition [21]. Ray h. arrison, Eric w. oreen, Peter c. Brewer, Wang Man translationManagement Accounting, 16th Edition, mechanical industry press, January 2019 Management Accounting [22].

\section{Conclusion}

Factor analysis has been widely used in practical economic practice, and the theoretical methods of factor analysis are interwoven in social science textbooks. Its wrong calculation method still has the tendency of spreading constantly; Its wrong analysis result, can misunderstand the function of the factor, the economic activity performance is not divided into responsibility; In medicine, the effects of the factors that lead to different compositions are unclear; The error calculated in the factor analysis in the experiment will lead to the failure of the whole experiment result, and the loss will be immeasurable. Factor analysis has come to the point where it has to be solved. In this paper, the sequel to the factor analysis factors of dispersion calculation data processing in the product structure, the factor of dispersion in the factor analysis product structure analysis results calculated by different method to compare ", will be carried out, and the true character of the factor analysis method, to uncover the mystery, the troubled social science techniques for factor analysis method in precise economic quantity calculation results, the comparison differences of different matters activities play a right role.

\section{References}

[1] Chen gang. Evaluation of enterprise marketing performance based on FTA factor analysis [J/OL]. Statistics and decision making, 2019 (10): 181-184 [2019-05-29]. https://doi.org/10.13546/j.cnki.tjyjc.2019.10.045.

[2] Li yong. Application of factor analysis method in the purchase and sales performance assessment of China's stored grain [J]. Enterprise reform and management, 2019 (02): 47-48. 
[3] Wang lei. Application of factor analysis in standard cost difference analysis [J]. Accountant, 2018 (09): 79-80.

[4] Li zhengwei. Business performance evaluation of e-commerce enterprises from the perspective of factor analysis [J]. Research on business economy, 2017 (24): 119-121.

[5] Hold high the flag. Discrimination and analysis from material cost analysis to ternary factor analysis [J]. National circulation economy, 2017 (21): 26-27.

[6] Li haiying. Application of factor analysis in financial analysis of automobile enterprises [J]. Value engineering, 2017, 36 (04): 29-30.

[7] Liu haitao, guo sicong. Inference model of factor analysis [J]. Journal of liaoning university of engineering technology (natural science edition), 2015, 34 (01): 124-128.

[8] Liu ying. Application of factor analysis in power marketing analysis [J]. Electronic manufacturing, 2014 (17): 215-216.

[9] Zhang qingling, zhang liyuan. Improvement and exploration of factor analysis method -- taking direct material cost as an example [J]. Finance and accounting communications, 2014 (29): 97-99.

[10] Wang jinyu. Discussion on the application of factor analysis in financial management [J]. Knowledge economy, 2014 (07): 110 .

[11] Zhang wenhai, wang fei. Revision of factor analysis -- spatial analysis based on three factors [J]. Journal of finance and accounting, 2013 (22): 108-110.

[12] Pang jing. Application of factor analysis in standard cost management $[\mathrm{J}]$. China securities and futures, 2012 (08): 112-113.

[13] Chen yiyun. Trap analysis based on factor analysis method of total asset return rate $[\mathrm{J}]$. Friends of accounting, 2012 (17): 49-51.

[14] James h. stock (USA) // mark w. Watson | editor-in-chief: Chen xin | translator: shen genxiang sun yan translated econometrics (third edition) [M]./2012-04-01 / Shanghai century gezhi. 2018 certified public accountant financial cost management [M]. April 5 by China finance and economics publishing house under China finance and economics publishing group.
[15] Srikant m. duatar Madhav v. rajan, management accounting $[\mathrm{M}]$. (translated by wang liyan, Chen jiashi, 1st edition, renmin university of China press, April 2015), chapter 13, flexible budget, difference and management control p 450-491.

[16] Charles t. hoorngren Srikant m. datar Madhav v. riajan, cost and management accounting (15th edition) translated by wang liyan and liu yingwen [M]. Renmin university of China press, June 2016 first edition, November 2017, 3rd printing.

[17] Roman 1. wai, Katherine Schipper, Jennifer Francis. Financial Accounting -- concept, method and application (the 14th edition of the original book of Financial Accounting) translated by zhu Dan and qu tenglong [M]. China machine press, September 2015, the first edition p 175-176.

[18] financial analysis, edited by zhang xianzhi and Chen youyou (national planning textbooks, national excellent courses and national excellent resource sharing courses for undergraduate courses of general higher education during the 12th five-year plan). Northeast university of finance and economics press, May 2018, the 37th printing [M].

[19] The Chinese association of certified public accountants organized and compiled the guidance textbook for the national unified examination of certified public accountants, financial cost management $[\mathrm{M}]$ China financial publishing and media group, China financial and economic publishing house, 1st edition p 29-30, March 2018.

[20] Meng yan, liu junyong, cost management accounting (higher education press printed a series of textbooks for accounting majors in colleges and universities for the third time in December 2017, and the national planning textbooks for undergraduate courses of general higher education during the 12th five-year plan) [M]. P 102-114.

[21] Tracie Nobles, Brenda Mattison, Ella Mae Matsumura. Horngren's accounting: management accounting sub-volume (the fourth edition of the original book), mechanical industry press, January 2017, 1st edition. P: 258-278.

[22] Ray h. arrison, Eric w. oreen, Peter c. Brewer, Wang Man translationManagement Accounting, 16th Edition, mechanical industry press, January 2019 Management Accounting. P 283-303. 